\title{
BİLYELİ DÖVME METODU İLE OTOMOTIV PARÇALARINDA ÇALIŞMA ÖMRÜNÜN ARTTIRILMASI
}

$\begin{array}{r}\text { F. YildizCAVDAR* } \\ \text { Serkan ÖZSAHIN*** } \\ \text { İsmail KUMPAS } \\ \text { Behiye KORKMAZ } \\ \text { Kadir ÇAVDAR } \\ \hline\end{array}$

Alınma:26.02.2018; düzeltme:30.07.2018; kabul:10.08.2018

Öz: Parça geometrisi ve malzeme özellikleri dikkate alındığında shot peening (SP, bilyeli dövme) süreci parçaya özgü imalat süreci tasarımı ve parametre tanımı gerektirmektedir. Bu, malzemenin mekanik ve yüzey özelliklerini iyileştirmeyi amaçlayan mekanik bir süreçtir. Özellikle dinamik yükler altında çalışan, burulma ve burkulmaya zorlanan parçalarda kullanılmaktadır. Dolayısıyla sürece birçok parametre etki etmektedir. Bu çalışmada, adım motorunun iki farklı açısal değerinde bilyeli dövme uygulama süreleri bağımsız parametreler olarak alınmış ve parça üzerinde konumlandırılan dört farklı Almen plakasından ölçülen deformasyon değerleri incelenmiştir. Ön deneylerde elde edilen bulgular doğrultusunda süreler üzerinde bazı değişiklikler öngörülmüştür. Tasarlanan ikinci deney seti sonrasında Almen plakalarının sonuçlarında istenen aralığa doğru bir iyileşme sağlanmıştır. Bilyeli dövme sürecinin daha fazla bağımsız değişken ile incelenmesi gerektiği sonucuna varılmıştır.

Anahtar Kelimeler: Bilyeli dövme, Otomotiv, Deney Tasarımı, Almen Plakaları

\section{Increasing of Fatigue Life of the Automotive Parts with Shot Peening Method}

Abstract: When part geometry and material properties are taken into consideration, shot peening (SP) process is required part specific process design and parameter definition. This process is a mechanical process aiming to improve the mechanical and surface properties of the material. It is particularly used for the parts which operate under dynamic loads and subjected to torsional and buckling forces. Therefore, many parameters are affected the process. In this study, shot peening durations at two different angular values of the stepper motor were taken as independent parameters and deformation values measured from 4 different Almen strips located on the part were investigated. In consideration of the findings obtained in the preliminary experiments, some changes on the peening durations are suggested. After the second set of designed experiments, some improvements in the direction of the appropriate range were achieved in the results of the Almen strips. It was concluded that the shot peening process should be examined with a greater number of independent variables.

Keywords: Shot peening, Automotive, Design of Experiment, Almen Strips

\footnotetext{
"FCB ArGe Mühendislik Hizmetleri Ltd. Şti., ULUTEK Teknopark, Z028, 16059, Bursa.

*** AKA Otomotiv A.Ş. ArGe Merkezi, Örnekköy Yolu 1. km., 16800 Orhangazi, Bursa.

**** Uludağ Üniversitesi, Mühendislik Fakültesi, Makine Mühendisliği Bölümü, 16059, Bursa. İletişim Yazarı: Fatma Yıldız Çavdar (cavdar@fcb-arge.com)
} 


\section{GİRIŞ̧}

Bilyeli dövme yönteminde metal malzemelerin yüzey ve içyapı özelliklerini değiştirmek amacıyla, malzemenin yüzeyine küçük, küresel ve sert bilyelerin kontrollü şekilde firlatılması işlemidir. Bu yöntemle malzeme yüzeyinde plastik deformasyon dolayısıyla kalıcı bası gerilmeli bir tabaka oluşturmaktır. Bu tabaka sayesinde malzemenin yorulma ömründe kayda değer artışlar elde edilebilir. Bilyeli dövme yöntemi bunun dışında malzeme yüzey temizliği için de kullanılmaktadır. Bu çalışmada, otomotivde kullanılan ve kaynak yöntemi ile imal edilen parçalarda Bilyeli dövme yöntemi ile sağlanabilecek avantajlar incelenmektedir. Süreç parametrelerinin etkileri ve nasıl kontrol altında tutulabileceği deneysel olarak araştırılmış ve çeşitli tecrübeler paylaşılmıştır.

Fonksiyonu gereği gerilim altında çalışan, korozyona ve sirküler yüklere maruz kalarak aşınan metal parçaların dayanımını artırmada ileri bir mekanik yüzey işlem prosesi olarak bilyeli dövme işlemi uygulanmaktadır. Bilyeli dövme işlemi esnasında metal yüzeylerin aşağıda belirtilen bazı önemli parametreleriyle oynanmaktadır.

Guechichi ve ark. (2013) tarafından hazırlanan çalışmada malzeme özelliklerinin iyileştirilmesinde kullanılan bir yöntem olan SP tanıtılmakta ve süreçte en önemli parametre olarak görülen bilyelerin hızı konusu üzerinde durulmaktadır. Hız tahminleri için kestirimci bir metot önerilmiştir. Bu metot yapılan deneyler ile benzer sonuçlara ulaşmıştır. Bilye boyutu, malzeme ve firlatma açısı parametreleri verildiğinde bilye hızı Almen yoğunluğuna bağlı olarak seçilebilmektedir. Sonuçta elde edilen diyagram aşağıda verilmiştir.

Gangaraj ve ark. (2014) tarafından hazırlanan makalede ise sonlu elemanlar yöntemini kullanarak SP yönteminin karakteristik büyüklüklerinin ve etkisinin belirlenmesi çalışmaları anlatılmaktadır. Sonlu elemanlar yöntemi Avrami denklemi ile benzer sonuçlar göstermiştir.

Reilley (2013) tarafından sunulan makalede hassas SP sistemi tanıtılmaktadır. Yeni bir konseptin oluşturulduğu savunulan çalışmada geleneksel SP sürecinin temel alındığı vurgulanmaktadır. Daha hassas bir lülenin kullanıldığı sistemde hareketler ve parçaya fokus olma otomatikman yapılmaktadır. Sistemin bir fotoğrafı aşağıda verilmiştir.

Gariepy ve ark. (2013) tarafından hazırlanan makalede bilyelerin yolunun sürece ve süreçteki parçanın değerlerine etkisi sonlu elemanlar yöntemi kullanılarak araştırılmıştır. Deneyler yardımı ile yaklaşım doğrulanmıştır. Endüstriyel uygulamalarda kullanılacak yaklaşım ile simülasyonların daha hızlı ve doğru şsekilde yapılabileceği böylece maliyetlerin düşürülebileceği vurgulanmaktadır.

Bagherifard ve ark. (2012) tarafindan sunulan çalışmada sonlu elemanlar simülasyonu yardımıyla SP yüzey durumunun tahmini konusu üzerinde durulmaktadır. SP metodunun en önemli kontrol parametresi olan yüzey durumu (surface coverage) sürecin uygulamasında karar parametresidir. Kalite kontrol parametresi olarak da kullanılır. Günümüzde henüz standart bir kontrol süreci ortaya konamamıştır. Bu nedenle mevcutta deneysel çalışmaların yanı sıra teorik ve bilgisayar destekli yaklaşımlar bulunmaktadır. Çalışmada bu yaklaşımlar ele alınarak uygun bir yöntem ortaya konmaya çalışılmıştır.

$\mathrm{Bu}$ çalışmaların dışında literatürde parçaların yorulma ömürlerine SP metodunun etkisini araştıran yayınlar da mevcuttur. Bu yayında diğerlerinden farklı olarak bilyeli dövme metodunun otomotiv sektöründe bir seri imalat uygulaması çalışması sunulmaktadır.

\section{DENEYSEL ÇALIŞMA}

AKA Otomotiv San. ve Tic. A.Ş. Ar-Ge Merkezi tarafından yürütülen "Otomotiv seri imalat uygulamalarında bilyeli dövme metodu kullanımının araştırılması ve sürece ilişkin makine geliştirilmesi” adlı proje kapsamında öngörülen deneysel çalışmalar iki aşamada gerçekleştirilmiştir. 


\section{1 Ön Deneylerden Elde Edilen Bulgular}

Ön deneyler olarak adlandırılabilecek olan ilk aşamada süreç üzerindeki değişkenlikler analiz edilmiş, parametreler belirlenmeye çalışılmış ve iki bağımsız değişken temel alınmıştır. Bunlar, adım motorunun iki farklı açı değerinde $\left(30^{\circ}\right.$ ve $\left.340^{\circ}\right)$ bilyeli dövme uygulama süresi olarak belirlenmiştir. Bağımlı değişkenler olarak ise 4 farklı Almen plakasından alınan deformasyon değerleri kararlaştırılmıştır. Ön deneylerde elde edilen veriler Tablo 1'de, ortalama ve standart sapma bilgileri ise Tablo 2'de verilmiştir.

Tablo 1. Ön deneylerde elde edilen sonuç verileri

\begin{tabular}{|c|c|c|c|c|c|}
\hline \multicolumn{2}{|c|}{ Bağımsız Değişkenler } & \multicolumn{4}{|c|}{ Bağıml Değişkenler } \\
\hline \multicolumn{2}{|c|}{ Uygulama Süresi (s) } & \multicolumn{4}{|c|}{ Almen Plakası Sonuçları $(\mu \mathrm{m})$} \\
\hline $30^{\circ}$ & $340^{\circ}$ & 1 & 2 & 3 & 4 \\
\hline 29 & 27 & 340 & 346 & 394 & 411 \\
\hline 29 & 27 & 325 & 324 & 371 & 386 \\
\hline 25 & 15 & 293 & 345 & 358 & 316 \\
\hline 15 & 25 & 300 & 372 & 355 & 297 \\
\hline 29 & 27 & 375 & 402 & 392 & 400 \\
\hline 29 & 27 & 414 & 383 & 382 & 424 \\
\hline 29 & 27 & 315 & 325 & 371 & 396 \\
\hline 29 & 27 & 364 & 325 & 358 & 421 \\
\hline 29 & 30 & 409 & 357 & 378 & 421 \\
\hline 29 & 27 & 410 & 419 & 406 & 400 \\
\hline 24 & 27 & 426 & 402 & 369 & 418 \\
\hline 29 & 20 & 402 & 353 & 372 & 429 \\
\hline 29 & 20 & 415 & 358 & 379 & 417 \\
\hline 29 & 27 & 455 & 407 & 373 & 417 \\
\hline 29 & 27 & 411 & 349 & 370 & 442 \\
\hline 29 & 27 & 427 & 372 & 406 & 428 \\
\hline
\end{tabular}

Tablo 2. Almen plakalarının ön deneylerde elde edilen tanımlayıcı istatistiki sonuçları

\begin{tabular}{|c|c|c|c|c|c|c|}
\hline Almen Plakas1 & Ort. & Std. Sapma & Varyans & Aralı & Min. & Maks. \\
\hline 1 & 380,06 & 50,74 & 2574,46 & 162,00 & 293,00 & 455,00 \\
\hline 2 & 364,94 & 30,54 & 933,00 & 95,00 & 324,00 & 419,00 \\
\hline 3 & 377,13 & 15,62 & 243,85 & 51,00 & 355,00 & 406,00 \\
\hline 4 & 401,44 & 39,76 & 1580,93 & 145,00 & 297,00 & 442,00 \\
\hline
\end{tabular}

Almen plakaları için sağlanması istenen değerler 400-440 $\mu \mathrm{m}$ arasındadır. Tablo 2 incelendiğinde ortalama değerlerde sadece 4 numaralı Almen plakasının bu aralığ sağladığı görülmektedir. Plakalara ait histogram grafikleri Şekil 1'de verilmiştir. Burada yeşil kesikli çizgiler istenen aralık sınırlarını, mavi çizgi ise ortalama değeri göstermektedir.

Histogramlar incelendiğinde 2 ve 3 nolu plakalardan elde edilen sonuçların istenen aralık dışında yığıldığı görülmektedir. 1 nolu plakada dağılımın kontrol edilebilir göründüğü, 4 nolu plakanın ise istenen aralığa daha kolay kaydırılabilecek bir dağılım sergilediği yorumu yapılabilir. Hedef tüm plakaların istenen aralıkta yoğun bir dağılım göstermesi olduğundan, sürecin ön deneylerde belirlenmiş olan bağımsız parametre aralıklarıyla kontrol altına alınamadığg söylenebilir.

Mevcut plaka ortalamaları ve standart sapması üzerinden normal dağılıma göre hesaplanan (beklenen) değerler ile gözlenen değerler arasındaki farkın gösterildiği Q-Q grafikleri Şekil 2'de gösterilmektedir. Burada doğru etrafındaki yayılım ve farklar üzerinden süreç eğilimleri ve normal dağılım uygunluğu yorumlanabilmektedir. Şekilden de görülebileceği gibi genel olarak 
plaka sonuçları normal dağılıma uygun verilerdir. Doğrunun çevresine yayılım olarak bakıldığında 4 nolu plakanın belirli bir eğilim sergilediği söylenebilir.

$30^{\circ}$ ve $340^{\circ}$ konumlarında bilyeli dövme uygulama sürelerinin Almen plaka sonuçları üzerinde oluşturduğu değişimleri incelemek amacıyla bağımsız değişken bazında ayrı ayrı kutu grafikleri çizilmiştir. Grafiklerde sıralanmış veri dizisinin orta yarısını (yani \%50'sini) kapsayan aralığın (istatistiksel yayılma) gösterildiği kutular üzerinden yorumlamalar yapılmıştır. $30^{\circ}$ için 3 farklı tekil değer dışında ağırlıklı olarak 29 saniyelik uygulama süreleriyle çalışıldığından, bu grafiklerden sadece ilgili uygulama süresi için Almen plakası bazındaki değişkenliklerin farkı irdelenmiştir (Şekil 3.).

Grafiklerde yeşil kesikli çizgiler istenen değer aralığını, mavi düz çizgi ise ortalama değeri ifade etmektedir. 29 saniye uygulama süresi için oluşan kutu grafikleri kıyaslandığında en düşük toplam değişkenliğin 3 numaralı Almen plakasında sağlandığı, ancak istenen aralıkta alt sınırın dışında kalma eğiliminin mevcut olduğu görülmektedir. Hem istenen aralıkta kalma hem de değişkenlik birlikte değerlendirildiğinde en uygun sonuçların 4 numaralı Almen plakasında alındığı söylenebilir. Her ne kadar tekil deneyler yapılabildiyse de 24 saniye uygulama süresi ile ilgili ek çalışmalar yapılabilir. 30 saniyenin de gözlenmesi, uygulama süresi artışının değişkenliğe etkisinin yorumlanmasında faydalı olabilir. İlgili konumda parça başına zaman kısıtından dolayı uygulama süresi arttırılamıyorsa, makinenin bilye püskürtme ile ilgili diğer parametrelerinin ele alınması faydalı olabilir.
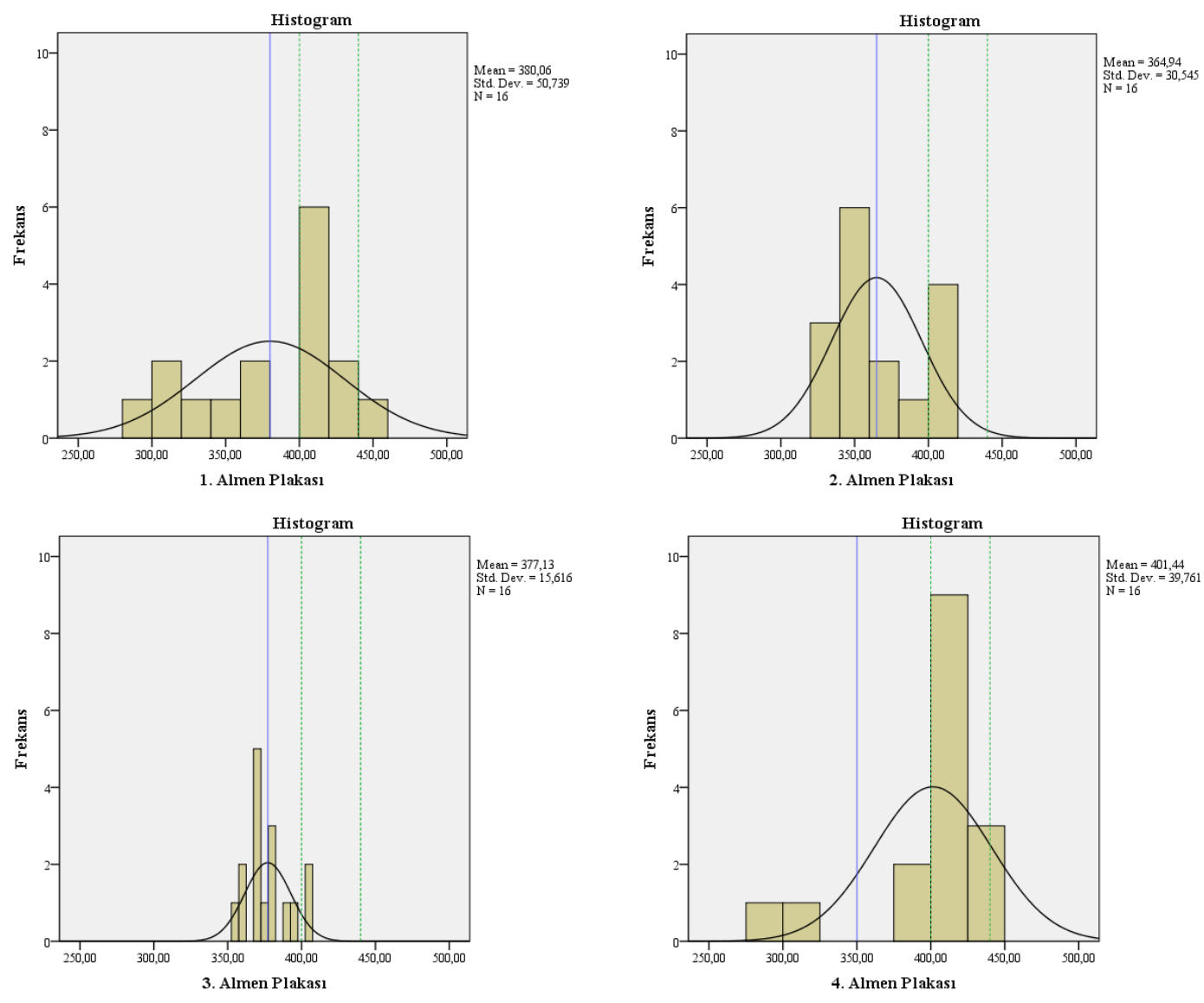

Şekil 1:

Almen plakalarına ilişkin ön deneylerde elde edilen sonuçlara ait histogramlar 

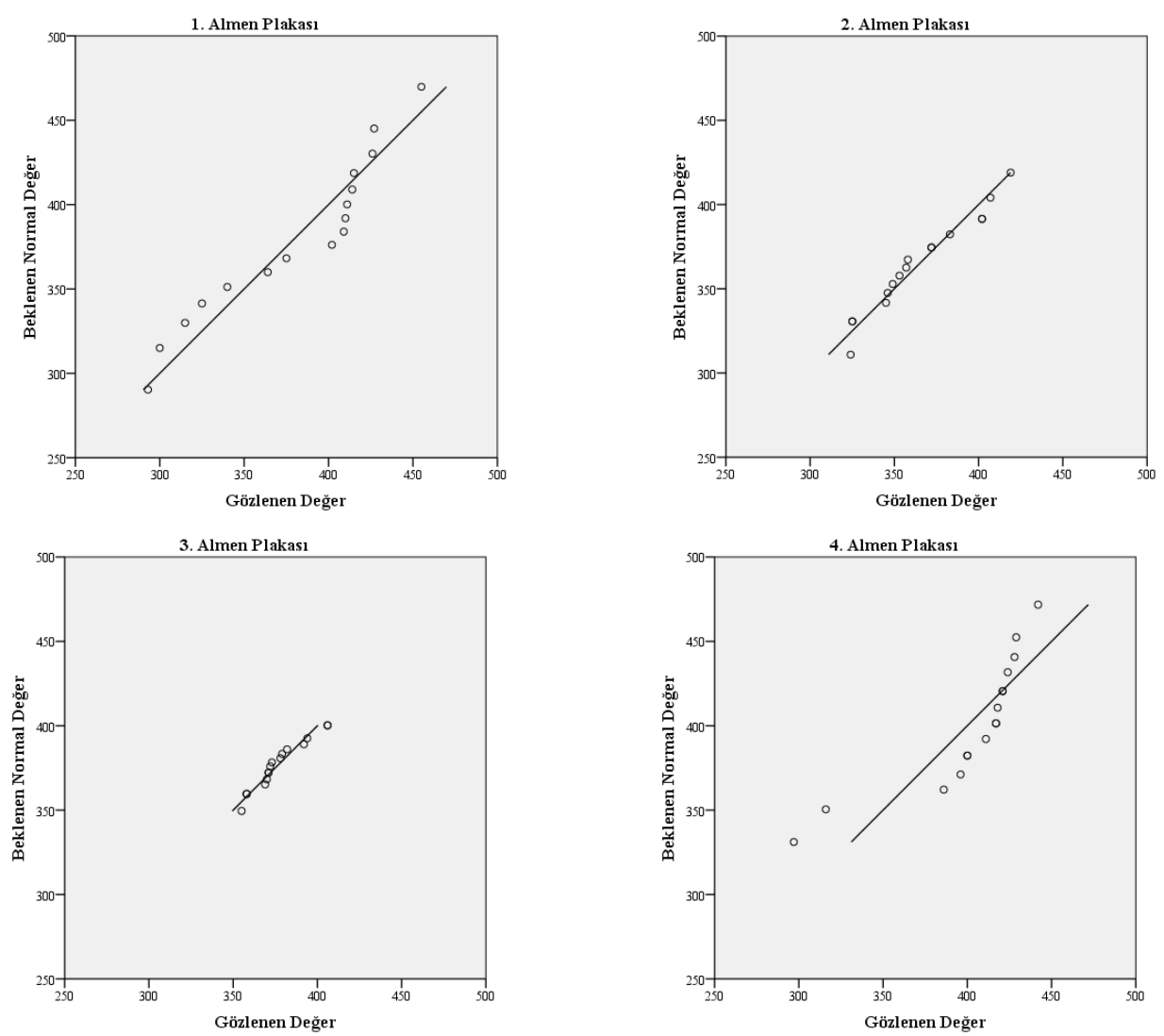

Şekil 2:

Ön deney sonuçlarının Almen plakaları bazında Q-Q grafikleri

$340^{\circ}$ konumunda 3 tekil süre denemesinin dışında 20 saniye için 2 adet, 27 saniye için ise 11 adet deneme yapılmıştır. Oluşturulan kutu grafiklerinde de (Şekil 4.) ağırlıklı olarak 27 saniyelik uygulama sürelerinde oluşan grafikler irdelenmiştir. Şekil 4 incelendiğinde istenen aralıktaki en uygun sonuçların ve en düşük değişkenliğin 4 numaralı Almen plakasında hem 20 hem de 27 saniyelik uygulama sürelerinde sağlandığı görülmektedir. Toplam değişkenlik açısından en iyi sonuçlar 3 numaralı Almen plakasında gözlenmekle birlikte sonuçlar istenen aralığın altında kalma eğilimindedir.

$340^{\circ}$ konumda süreç eniyileme stratejisi olarak daha düşük uygulama sürelerinin etkilerini incelemek anlamlı olabilir. Bu şekilde $30^{\circ}$ konumda temel alınan sürenin arttırılmasının parça başına süreye yansıması da telafi edilebilir.

Plakalar arasındaki farklılıklar sürecin, uygulama parçasının her bölgesinde aynı etkinlikte olmadığını düşündürmektedir. Bilyelerin vuruş etkisinin 3 numaralı plaka civarında optimuma yakın olduğu söylenebilir. Parça üzerinde bilyeli dövme uygulanan tüm bölgenin aynı etkinlikte bir uygulamaya maruz bırakılması için gerekli olabilecek konstrüktif çözümler araştırılmalıdır.

Ön deneylerin sonuçlarına ilişkin korelasyon tablosu Tablo 3 'te görülmektedir. Tüm Almen plakalarının birbiriyle yüksek korelasyona sahip olması beklenmesine rağmen bu korelasyonun mevcut düzenekte sağlanamadığı tespit edilmiştir. Dolayısıyla bilyeli dövme makinesinde tüm bölgenin aynı şekilde sürece maruz kalmadığ 1 yorumu yapılabilir. 1 ve 2 nolu plakalar parçanın üst bölgesinde 3 ve 4 nolu plakalar ise alt bölgesinde yer almaktadır. 1-2 arasında net bir korelasyon görülürken 3-4 arasında kısmen var olduğu düşünülebilecek bir korelasyon mevcuttur. Dolayısıyla sürecin alt bölgede ve üst bölgede, bölgesel olarak aynı etkinlikte olduğu söylenebilir. 1 ve 4 nolu plakalar arasındaki net korelasyonu ise çapraz doğrultuda bilye vuruş etkisinin tutarlılığı şeklinde yorumlamak mümkündür. 

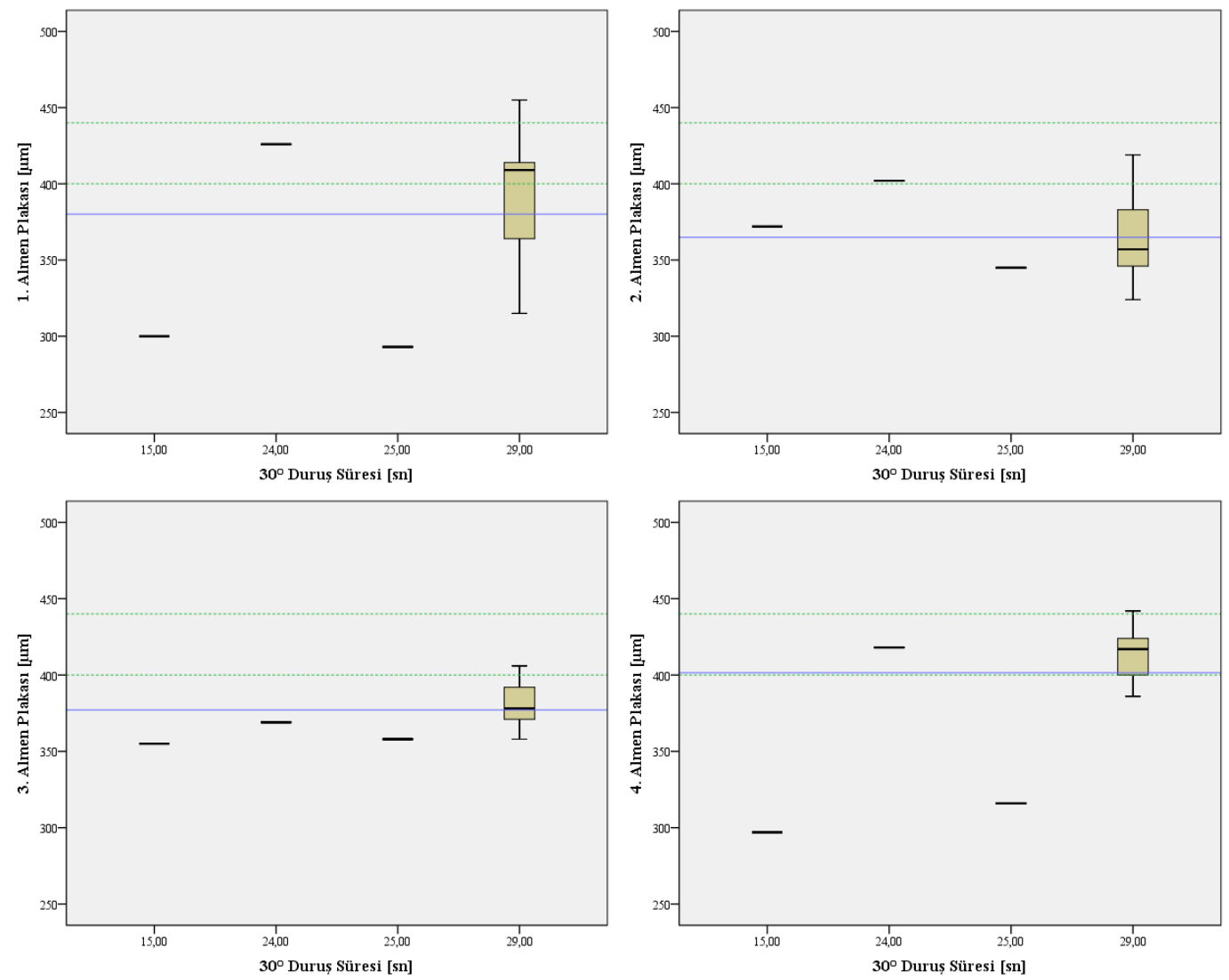

Şekil 3:

$30^{\circ}$ konumda uygulama sürelerine göre Almen plakası sonuçlarına ait kutu grafikleri

Bağımsız değişenlerin birbiriyle korelasyon katsayısı sıfır olmadığından birbirlerinden tamamen bağımsız olmadıkları yorumu yapılabilir. Bağımsız değişkenlerden $30^{\circ}$ ' deki uygulama süresinin 4 nolu plaka sonuçları ile net bir korelasyona sahip olduğu görülmektedir. 1 ve 3 nolu plakalarla da kısmen korelasyona sahiptir. Ancak 2 nolu plaka ile korelasyonu oldukça düşüktür. Motorun bu konumundaki püskürtme süresinin en fazla 4 nolu plakayı etkilediği söylenebilir. İlgili konumun 2 nolu plaka sonuçlarını etkilediğine dair bir bulgu yoktur. Etki sıralamas $4>3>1>2$ şeklindedir.

$340^{\circ}$ 'deki uygulama süresinin hiçbir plaka sonucuyla net korelasyonu yoktur. Korelasyon katsayılarına bakıldığında ise $30^{\circ}$ 'deki sonuçlara göre daha düşük etkide olmak üzere aynı yorum yapılabilir. Etki sıralaması $4>3>1>2$ şeklindedir.

Test edilen plakaların ortalama Almen test sonuçları arasındaki farkların önemli olup olmadığına yönelik bilgi edinmek amacıyla, plakalardan eşleştirilmiş örnekler arasında T-Testi uygulanmıştır. $\mathrm{Bu}$ testte sıfir hipotezi ortalamalar arasında önemli bir fark olmadığ 1 , karşı hipotez ise önemli bir fark olduğu şeklinde kurulmakta ve karar ölçütü olarak bulunan $p$ değerinin $\alpha(=0,05)$ ile kıyaslaması yapılmaktadır. $\mathrm{p}<\alpha$ durumunda sıfır hipotezi reddedilmekte ve sonuç, ortalamalar arasında önemli bir fark olduğu şeklinde yorumlanmaktadır. Tersi durumda farkın önemli olmadığı yorumu yapılabilmektedir.

Ön deneylerde elde edilen verilerle Almen plakalarının karşılıklı olarak test edildiği sonuçlar Tablo 4'te verilmiştir. Burada 4 nolu plakanın diğer plakalara göre ortalama değer farkının önemli olduğu, diğer eşleşmeler arasında önemli bir fark olmadığı görülmektedir. Buradan bilyeli dövme sürecinin 4 nolu plaka civarında, diğer plakalara göre farklı etki ettiği söylenebilir. 

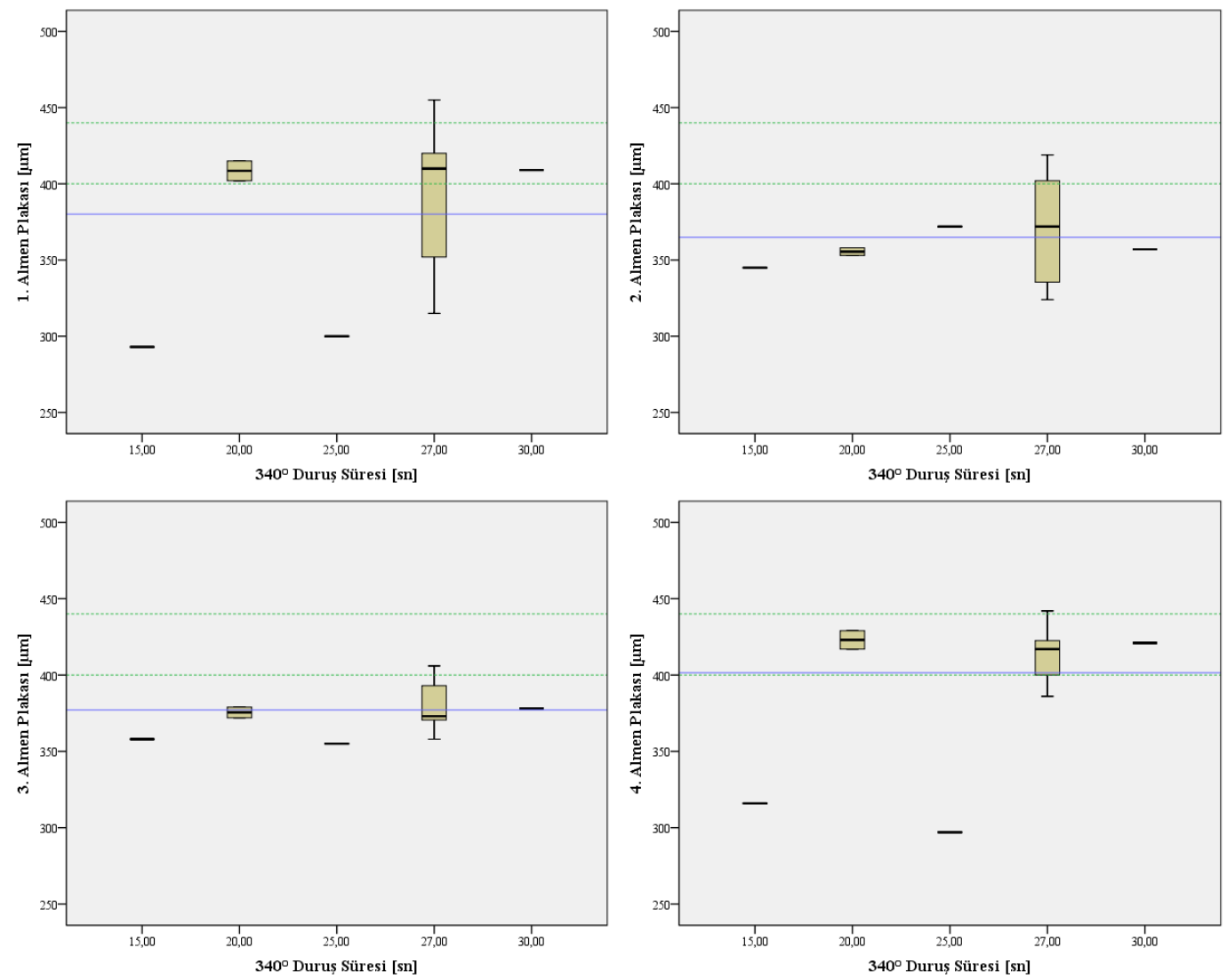

Şekil 4:

$340^{\circ}$ konumda uygulama sürelerine göre Almen plakası sonuçlarına ait kutu grafikleri

Tablo 3. Ön deneylere ait korelasyon tablosu

\begin{tabular}{|c|c|c|c|c|c|c|c|}
\hline Değişken & & $\begin{array}{c}30^{\circ} \\
\text { Uygulama } \\
\text { Süresi }\end{array}$ & $\begin{array}{c}340^{\circ} \\
\text { Uygulama } \\
\text { Süresi }\end{array}$ & $\begin{array}{l}\text { 1. Almen } \\
\text { Plakas1 }\end{array}$ & $\begin{array}{c}\text { 2. Almen } \\
\text { Plakası }\end{array}$ & $\begin{array}{l}\text { 3. Almen } \\
\text { Plakas1 }\end{array}$ & $\begin{array}{l}\text { 4. Almen } \\
\text { Plakas1 }\end{array}$ \\
\hline \multirow[t]{3}{*}{$\begin{array}{l}30^{\circ} \text { Uygulama } \\
\text { Süresi }\end{array}$} & $\begin{array}{l}\text { Pearson } \\
\text { Korelasyonu }\end{array}$ & 1 & 0,191 & 0,442 & $-0,121$ & 0,494 & $0,783^{\text {**F }}$ \\
\hline & Önem (cift yönlü) & & 0,479 & 0,087 & 0,655 & 0,052 & 0,000 \\
\hline & $\mathrm{N}$ & 16 & 16 & 16 & 16 & 16 & 16 \\
\hline \multirow{3}{*}{$\begin{array}{l}340^{\circ} \\
\text { Uygulama } \\
\text { Süresi }\end{array}$} & $\begin{array}{l}\text { Pearson } \\
\text { Korelasyonu }\end{array}$ & 0,191 & 1 & 0,309 & 0,192 & 0,337 & 0,438 \\
\hline & Önem (çift yönlü) & 0,479 & & 0,244 & 0,477 & 0,202 & 0,090 \\
\hline & $\mathrm{N}$ & 16 & 16 & 16 & 16 & 16 & 16 \\
\hline \multirow[t]{3}{*}{$\begin{array}{l}\text { 1. Almen } \\
\text { Plakası }\end{array}$} & $\begin{array}{l}\text { Pearson } \\
\text { Korelasyonu }\end{array}$ & 0,442 & 0,309 & 1 & $0,578^{*}$ & 0,437 & $0,766^{\text {**6 }}$ \\
\hline & Önem (çift yönlü) & 0,087 & 0,244 & & 0,019 & 0,091 & 0,001 \\
\hline & $\mathrm{N}$ & 16 & 16 & 16 & 16 & 16 & 16 \\
\hline \multirow[t]{3}{*}{$\begin{array}{l}\text { 2. Almen } \\
\text { Plakası }\end{array}$} & $\begin{array}{l}\text { Pearson } \\
\text { Korelasyonu }\end{array}$ & $-0,121$ & 0,192 & $0,578^{*}$ & 1 & 0,454 & 0,074 \\
\hline & Önem (çift yönlü) & 0,655 & 0,477 & 0,019 & & 0,077 & 0,786 \\
\hline & $\mathrm{N}$ & 16 & 16 & 16 & 16 & 16 & 16 \\
\hline \multirow[t]{3}{*}{$\begin{array}{l}\text { 3. Almen } \\
\text { Plakası }\end{array}$} & $\begin{array}{l}\text { Pearson } \\
\text { Korelasyonu }\end{array}$ & 0,494 & 0,337 & 0,437 & 0,454 & 1 & 0,439 \\
\hline & Önem (çift yönlü) & 0,052 & 0,202 & 0,091 & 0,077 & & 0,089 \\
\hline & $\mathrm{N}$ & 16 & 16 & 16 & 16 & 16 & 16 \\
\hline \multirow[t]{3}{*}{$\begin{array}{l}\text { 4. Almen } \\
\text { Plakası }\end{array}$} & $\begin{array}{l}\text { Pearson } \\
\text { Korelasyonu }\end{array}$ & $0,783^{* *}$ & 0,438 & $0,766^{* *}$ & 0,074 & 0,439 & 1 \\
\hline & Önem (çift yönlü) & 0,000 & 0,090 & 0,001 & 0,786 & 0,089 & \\
\hline & $\mathrm{N}$ & 16 & 16 & 16 & 16 & 16 & 16 \\
\hline
\end{tabular}

**Korelasyon 0,01 seviyesinde önemlidir (çift yönlü). *Korelasyon 0,05 seviyesinde önemlidir (çift yönlü). 
Tablo 4. Ön deneylerde elde edilen plaka sonuçlarına ait eşleştirilmiş iki örnek T-Testi sonuçları

\begin{tabular}{|c|c|c|c|c|c|c|c|c|}
\hline \multirow{3}{*}{$\begin{array}{l}\text { Eşleştirilmiş } \\
\text { Plakalar }\end{array}$} & \multicolumn{5}{|c|}{ Eşleştirilmiş Farklar (Paired Differences) } & \multirow[t]{3}{*}{$\mathrm{t}$} & \multirow[t]{3}{*}{$\mathrm{df}$} & \multirow{3}{*}{$\begin{array}{l}\text { Önem (Çift } \\
\text { Yönlü Test) }\end{array}$} \\
\hline & \multirow[t]{2}{*}{ Ortalama } & \multirow{2}{*}{$\begin{array}{l}\text { Standart } \\
\text { Sapma }\end{array}$} & \multirow{2}{*}{$\begin{array}{c}\text { Standart } \\
\text { Hata Ort. }\end{array}$} & \multicolumn{2}{|c|}{ \%95 Fark Güven Aralığ1 } & & & \\
\hline & & & & Alt & Üst & & & \\
\hline $1-2$ & 15,12500 & 41,44052 & 10,36013 & $-6,95709$ & 37,20709 & 1,460 & 15 & 0,165 \\
\hline $1-3$ & 2,93750 & 46,11358 & 11,52840 & $-21,63469$ & 27,50969 & 0,255 & 15 & 0,802 \\
\hline $1-4$ & $-21,37500$ & 32,63102 & 8,15775 & $-38,76284$ & $-3,98716$ & $-2,620$ & 15 & 0,019 \\
\hline $2-3$ & $-12,18750$ & 27,26956 & 6,81739 & $-26,71843$ & 2,34343 & $-1,788$ & 15 & 0,094 \\
\hline $2-4$ & $-36,50000$ & 48,31563 & 12,07891 & $-62,24558$ & $-10,75442$ & $-3,022$ & 15 & 0,009 \\
\hline 3-4 & $-24,31250$ & 35,76725 & 8,94181 & $-43,37152$ & $-5,25348$ & $-2,719$ & 15 & 0,016 \\
\hline
\end{tabular}

\section{2 İkinci Deney Setinde Elde Edilen Bulgular}

İkinci deney setinde ön deneylerde elde edilen bulguların doğrulanması ve farklı uygulama sürelerinin getireceği sonuçların görülmesi hedeflenmiştir. $\mathrm{Bu}$ deneylerde temel alınan uygulama süreleri ve elde edilen Almen plaka sonuçları Tablo 5'te, ortalama ve standart sapma bilgileri ise Tablo 6'da görülmektedir.

İstenen değer aralığı $(400-440 \mu \mathrm{m})$ olarak bakıldığında 3 nolu Almen plakasından en iyi sonuçların alındığı görülmektedir. Ortalama olarak istenen aralıkta kalmasının yanında değişkenliği de tüm plakalar içerisinde en düşük olan plaka 3 nolu Almen plakasıdır. 1 ve 2 nolu plakaların ortalama değerlerinin neredeyse aynı gelmesi bu bölgede süreç etkinliğinin homojen duruma yaklaştı̆̆ 1 şeklinde yorumlanabilir.

İkinci deney setinde Almen plakalarından elde edilen sonuçlara ilişkin histogram grafikleri Şekil 5'te verilmiştir. Histogramlar incelendiğinde değişkenliğin kontrol altına alınmasıyla tüm plakalarda sürecin kontrol altına alınabilir olduğu söylenebilir. Mevcut standart sapma değerlerinin, istenen değer aralığını sağlamak açısından çok yüksek olduğu görülmektedir.

Tablo 5. Íkinci deney setinde elde edilen sonuç verileri

\begin{tabular}{|c|c|c|c|c|c|}
\hline \multicolumn{2}{|c|}{ Bağımsız Değişkenler } & \multicolumn{5}{|c|}{ Bağıml Değişkenler } \\
\hline \multicolumn{2}{|c|}{ Uygulama Süresi (sn) } & \multicolumn{4}{|c|}{ Almen Plakası Sonuçları $(\mu \mathrm{m})$} \\
\hline $30^{\circ}$ & $340^{\circ}$ & 1 & 2 & 3 & 4 \\
\hline 15 & 15 & 322 & 330 & 414 & 329 \\
\hline 13 & 2 & 290 & 310 & 400 & 340 \\
\hline 15 & 5 & 330 & 360 & 430 & 290 \\
\hline 15 & 15 & 320 & 340 & 420 & 350 \\
\hline 20 & 15 & 330 & 370 & 420 & 360 \\
\hline 30 & 15 & 350 & 350 & 400 & 360 \\
\hline 30 & 15 & 370 & 360 & 420 & 380 \\
\hline 30 & 15 & 370 & 360 & 400 & 360 \\
\hline 34 & 19 & 400 & 390 & 410 & 390 \\
\hline 36 & 21 & 410 & 400 & 430 & 410 \\
\hline 15 & 5 & 320 & 340 & 420 & 350 \\
\hline 25 & 17 & 460 & 370 & 420 & 400 \\
\hline 3 & 13 & 500 & 430 & 420 & 460 \\
\hline 20 & 10 & 476 & 404 & 400 & 415 \\
\hline 15 & 10 & 440 & 470 & 460 & 370 \\
\hline 13 & 10 & 480 & 470 & 450 & 365 \\
\hline 18 & 10 & 430 & 470 & 470 & 360 \\
\hline 12 & 6 & 426 & 430 & 440 & 345 \\
\hline 12 & 10 & 420 & 460 & 440 & 320 \\
\hline 8 & 10 & 430 & 456 & 456 & 358 \\
\hline
\end{tabular}


Tablo 6. Almen plakalarının ikinci deney setinden elde edilen tanımlayıcı istatistiki sonuçları

\begin{tabular}{|c|c|c|c|c|c|c|}
\hline Almen Plakas1 & Ort. & Std. Sapma & Varyans & Aralık & Min. & Maks. \\
\hline 1 & 393,70 & 62,67804 & 3928,537 & 210,00 & 290,00 & 500,00 \\
\hline 2 & 393,50 & 52,21766 & 2726,684 & 160,00 & 310,00 & 470,00 \\
\hline 3 & 426,00 & 20,91587 & 437,474 & 70,00 & 400,00 & 470,00 \\
\hline 4 & 365,60 & 37,14325 & 1379,621 & 170,00 & 290,00 & 460,00 \\
\hline
\end{tabular}
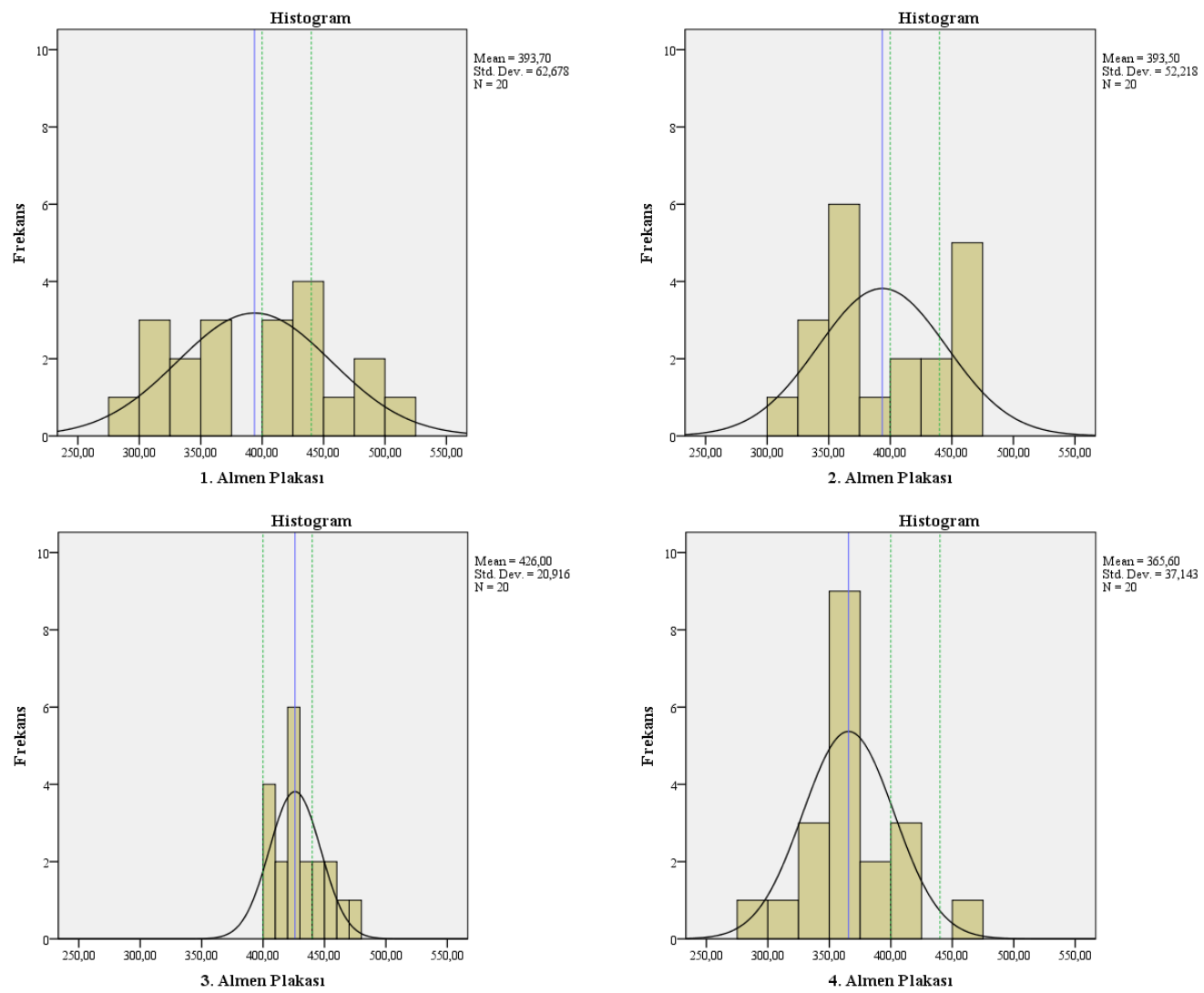

Şekil 5:

Almen plakalarına ilişkin ikinci set deneylerde elde edilen sonuçlara ait histogramlar

İkinci deney seti sonuçlarına ait Q-Q grafikleri Şekil 6'da görülmektedir. Grafikler incelendiğinde tüm plaka sonuçlarının normal dağılıma uygun olduğu ve gözlenen değerlerin doğrunun her iki tarafına yayılımı açısından herhangi bir net eğilim sergilenmediği söylenebilir. İkinci deney setinden elde edilen sonuçlarda da öncelikle bağımsız değişkenler bazında kutu grafikleri oluşturulmuş ve süre farklılıklarının Almen plakası sonuçları üzerinde yarattığı etki irdelenmiştir. $30^{\circ}$ konumunda uygulama süreleri ve plakalar bazında oluşturulan kutu grafikleri Şekil 7'de görülmektedir. Görselleştirmede yeşil kesikli çizgiler istenen değer aralığını, mavi çizgi ise plakaya ait ortalama sonucu göstermektedir.

1 ve 2 numaralı Almen plakaları için grafik üzerinden yorum yapmak uygun görünmemektedir. 3 numaralı plakada değerlerin, maksimum seviyenin üstünde kalan sonuçlar dışında tüm uygulama sürelerinde genel olarak istenen aralıkta kaldığı görülmektedir. 4 numaralı plakada süre arttırıldıkça Almen değerlerinde yukarıya doğru net bir eğilim gözlenmektedir. Aynı yorum $340^{\circ}$ konumundaki sonuçlar (Şekil 8) için de yapılabilir.

$340^{\circ}$ konumda daha düşük uygulama sürelerinin etkileri incelendiğinde 6-13 saniye aralığında 4 nolu plaka dışında istenen aralıkta sonuçlara ulaşıldığı gözlenmektedir. Ancak 4 
nolu plaka üzerindeki etkilerinin araştırılması için daha fazla sayıda deney yapılmasına ihtiyaç olduğu görülmektedir. Plakalar arasındaki farklılıklar sürecin, uygulama parçasının her bölgesinde aynı etkinlikte olmadığını düşüncesini güçlendirmektedir. Bilyelerin vuruş etkisinin 3 numaralı plaka civarında optimuma yakın olduğu söylenebilir. Parça üzerinde bilyeli dövme uygulanan tüm bölgenin aynı etkinlikte bir uygulamaya maruz bırakılması için gerekli olabilecek konstrüktif çözümlerin araştırılmasına devam edilmelidir.

İkinci deney sonuçlarına ilişkin korelasyon tablosu Tablo 7'de görülmektedir. Plakalar arası korelasyonların iki deney seti arasında yapılmış olan iyileştirmeler ile bu deney setinde arttığı gözlenmektedir. 1-2, 1-4 ve 2-3 nolu plakalar arasında net bir korelasyon yakalanmıştır. Çapraz plakalar arasında sağlanan bu korelasyon bilye vuruşlarında daha geniş bir alanda etkinliğin yakalandığ 1 şeklinde yorumlanabilir. 1-2 nolu plakalar arasındaki korelasyon parçanın üst uygulama bölgesinde yer alan plakalar arasında da benzer süreç etkinliğinin sağlandığını düşündürmektedir.

Ön deney setinde de bağımsız değişkenlerin birbiriyle korelasyonunun sıfir olmamasından hareketle tamamen bağımsız olmadıkları şeklinde yapılan yorum, bu deney setinde net bir korelasyon şekline dönüşmüştür. Dolayısıyla bir bağımsız değişken üzerinde yapılan değişimin, -diğeri değiştirilmese dahi- sonuçlar üzerinde her ikisinden kaynaklı bir farklılaşmaya yol açacağı bilinmelidir. $\mathrm{Bu}$ durum sürecin ilgili bağımsız değişkenler üzerinden kontrolünün oldukça karmaşık hale gelmesine sebep olabilir. Seçilen bağımsız değişkenlerin değiştirilmesi ve sonraki deneylere farklı bağımsız değişkenlerin katılması gerekmektedir.
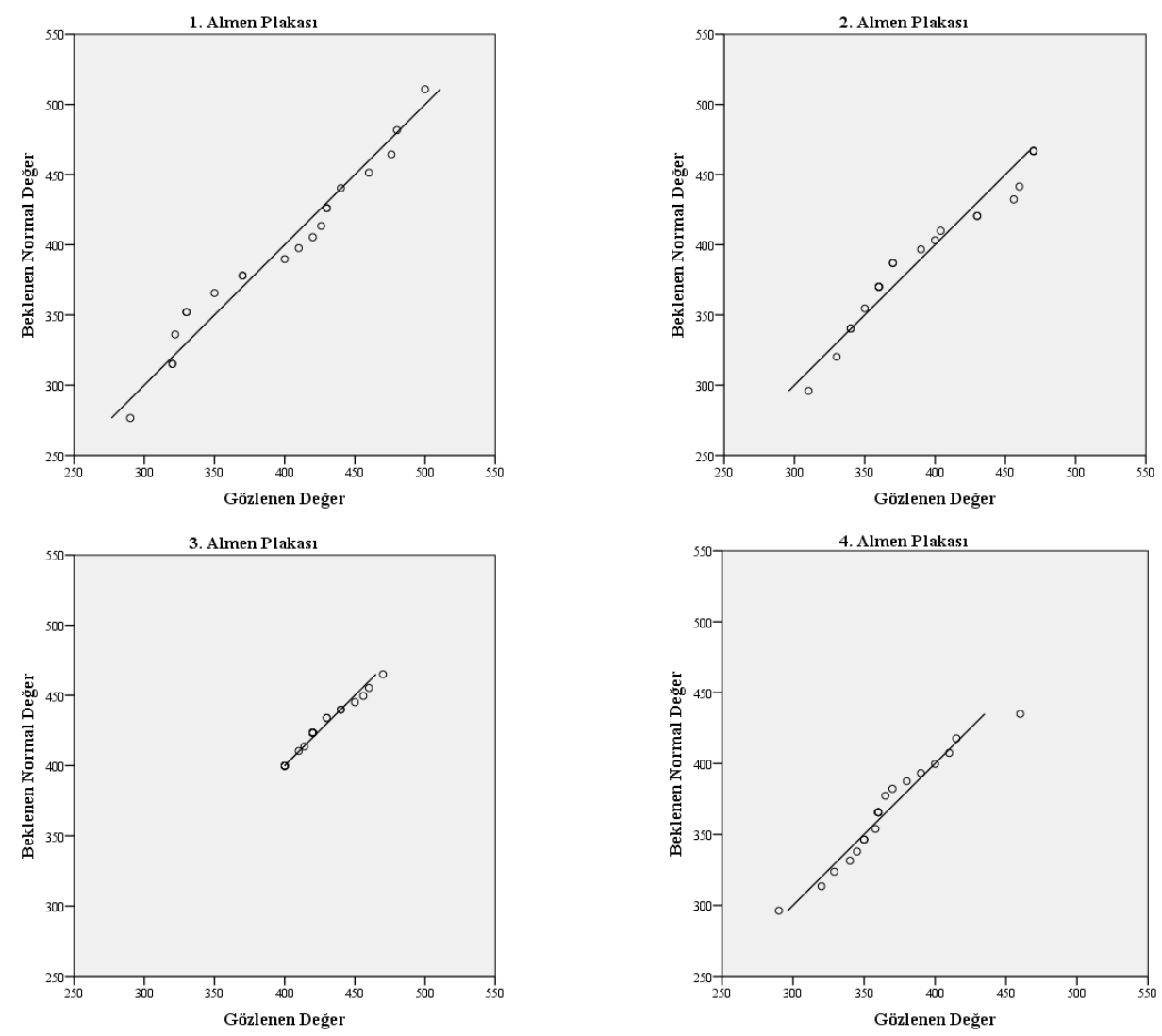

Şekil 6:

İkinci deney seti sonuçlarının Almen plakaları bazında Q-Q grafikleri 

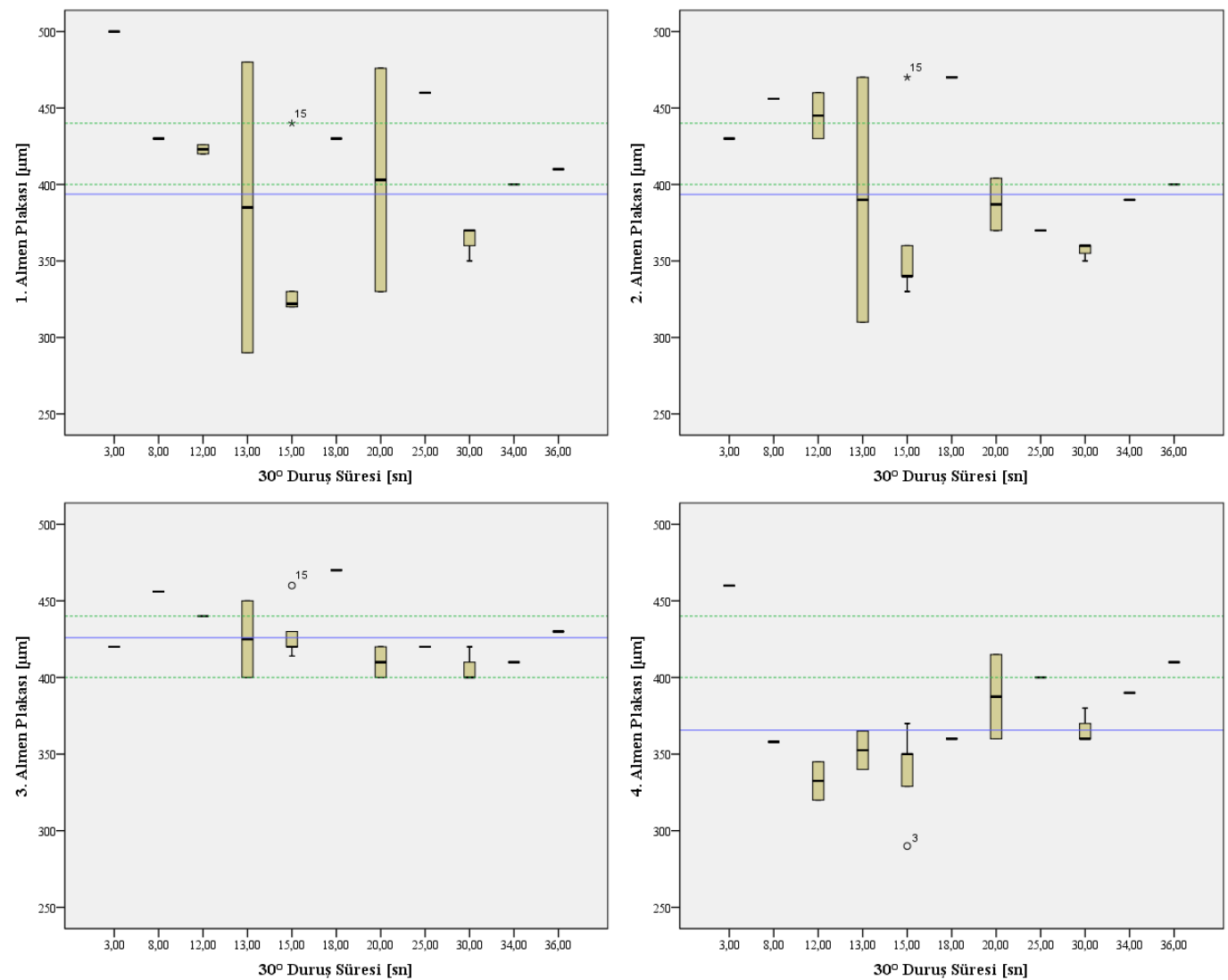

Şekil 7:

$30^{\circ}$ konumda uygulama sürelerine göre Almen plakası sonuçlarına ait kutu grafikleri

$30^{\circ}$ 'deki uygulama süresi hiçbir plaka ile önemli düzeyde ilişkili değildir. $340^{\circ}$ 'deki uygulama süresi ise 4 nolu plaka ile ilişkili görünmektedir. Sol alt plaka olan 4 nolu Almen plakasının, $340^{\circ}$ 'deki uygulama süresi değişimiyle net ilişkili sonuçlar vermiş olduğu söylenebilir. Bununla birlikte diğer plakalarda korelasyon bulunmamasından hareketle $340^{\circ}$ 'deki uygulama süresi değişiminin diğer plakalar üzerinde bir etkisi olmadığı yorumu yapılabilir.

Eşleştirilmiş plakaların Almen testi sonuç ortalamaları arasındaki farkların önemli olup olmadığına dair yapılmış olan T-Testi sonuçları Tablo 8'de verilmiştir. Görüldüğü gibi 1 ve 2 nolu plakaların kendi aralarında ortalamaları arasında önemli bir fark gözlenemezken diğer tüm eşleşmelerde ortalamalar arasında önemli bir fark söz konusudur. Dolayısıyla sürecin uygulandığ söylenebilir.

\section{SONUCCLAR}

Yapılan deneylerle elde edilen temel sonuçlar şu şekilde özetlenebilir:

- Almen plaka sonuçları arasındaki farklılıklardan yola çıkılarak, bilyeli dövme sürecinin uygulama parçasının tüm bölgelerinde istenen düzeyde bir homojen etki göstermediği söylenebilir.

- İkinci set deneylerde, başlangıçta belirlenmiş olan bağımsız değişenlerin birbiriyle korelasyona sahip olduğu netleşmiştir. Yeni belirlenecek bağımsız değişkenlerle deneylerin sürdürülmesinde fayda görülmektedir. 
Çavdar F.Y., Özşahin S., Kumpas İ., Korkmaz B., Çavdar K.: Bilyeli Dövme Metodu
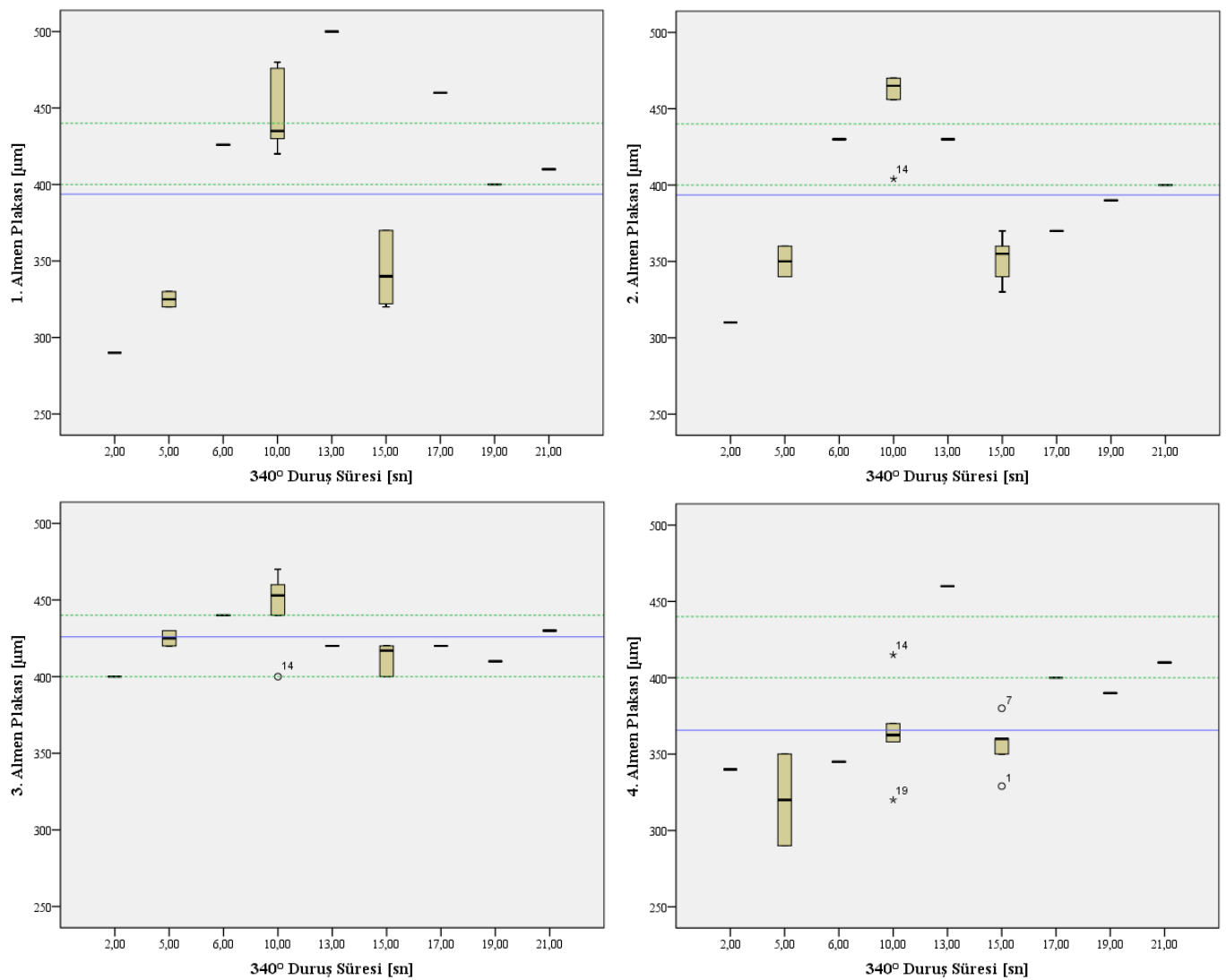

Şekil 8:

$340^{\circ}$ konumda uygulama sürelerine göre Almen plakası sonuçlarına ait kutu grafikleri

Tablo 7. İkinci deney setine ait korelasyon tablosu

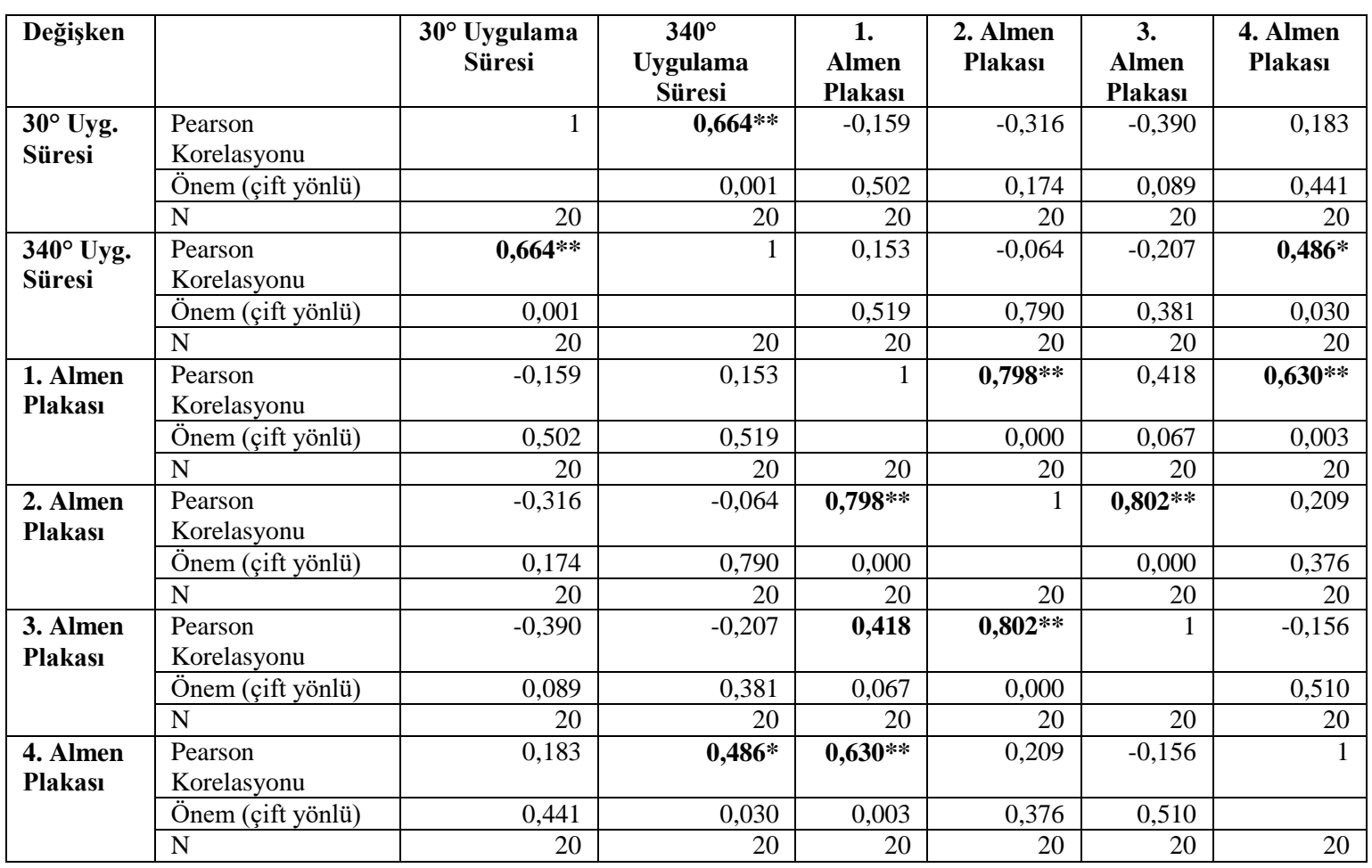

**Korelasyon 0,01 seviyesinde önemlidir (2-tailed). *Korelasyon 0,05 seviyesinde önemlidir (2-tailed) 
Tablo 8. İkinci deney setinde elde edilen plaka sonuçlarına ait eşleştirilmiş iki örnek T-Testi sonuçları

\begin{tabular}{|c|c|c|c|c|c|c|c|c|}
\hline \multirow{3}{*}{$\begin{array}{l}\text { Eşleştirilmiş } \\
\text { Plakalar }\end{array}$} & \multicolumn{5}{|c|}{ Çift Yönlü Farklar } & \multirow[t]{3}{*}{$\mathrm{t}$} & \multirow[t]{3}{*}{$\mathrm{df}$} & \multirow{3}{*}{$\begin{array}{l}\text { Sig. (2- } \\
\text { tailed) }\end{array}$} \\
\hline & \multirow[t]{2}{*}{ Ortalama } & \multirow{2}{*}{$\begin{array}{c}\text { Std. } \\
\text { Sapma }\end{array}$} & \multirow{2}{*}{$\begin{array}{c}\text { Std. Ort. } \\
\text { Hata }\end{array}$} & \multicolumn{2}{|c|}{ 95\% Güvenilirlik Aralığ1 } & & & \\
\hline & & & & Alt & Üst & & & \\
\hline $1-2$ & 0,20000 & 37,86347 & 8,46653 & $-17,52065$ & 17,92065 & 0,024 & 19 & 0,981 \\
\hline $1-3$ & $-32,30000$ & 57,19137 & 12,78838 & $-59,06638$ & $-5,53362$ & $-2,526$ & 19 & 0,021 \\
\hline $1-4$ & 28,10000 & 48,74628 & 10,90000 & 5,28604 & 50,91396 & 2,578 & 19 & 0,018 \\
\hline $2-3$ & $-32,50000$ & 37,58989 & 8,40536 & $-50,09261$ & $-14,90739$ & $-3,867$ & 19 & 0,001 \\
\hline $2-4$ & 27,90000 & 57,40337 & 12,83578 & 1,03439 & 54,76561 & 2,174 & 19 & 0,043 \\
\hline $3-4$ & 60,40000 & 45,38769 & 10,14900 & 39,15791 & 81,64209 & 5,951 & 19 & 0,000 \\
\hline
\end{tabular}

- $30^{\circ}$ konumda uygulama süresinin süreç sonuçları üzerinde daha fazla etki yaptığı gözlenmiştir. $340^{\circ}$ konumundaki süre kısmen aşağıya çekilerek optimizasyona gidilebilir.

Deney sonuçları, iki deney seti süresince gerçekleştirilen iyileştirmelerin süreç sonuçlarında istenen aralık açısından fayda sağladığını doğrulamıştır.

Daha sonraki çalışmalarda, bağımsız değişkenlerin arttırılarak yeni deneysel tasarımların yapılması, gerçekleştirilecek olan konstrüktif iyileştirmeler sonrasında deneylerin tekrarlanması, ele alınan ve proje kapsamında geliştirilmiş olan makinenin, muadil bir makineyle aynı deney seti üzerinden kıyaslanması ve sonuçların doğrulanması planlanmıştır.

\section{TEŞEKKÜR}

$\mathrm{Bu}$ çalışma Türkiye Bilimsel ve Teknolojik Araştırma Kurumu Teknoloji ve Yenilik Destek Programları Başkanlığı (TÜBİTAK TEYDEB) tarafından Sanayi AR-GE Projeleri Destekleme Programı kapsamında 3140906 numaralı ve "Otomotiv Seri İmalat Uygulamalarında Shot Peening Metodu Kullanımının Araştırılması ve Sürece İlişkin Makine Geliştirilmesi” adlı proje kapsamında desteklenmiştir.

\section{KAYNAKLAR}

1. Bagherifard, Ghelichi, S.R. ve Guagliano M. (2012) On the shot peening surface coverage and its assessment by means of finite element simulation: A critical review and some original developments, Applied Surface Science 259, 186- 194. doi: 10.1016/j.apsusc.2012.07.017

2. Gangaraj, S.M.H., Guagliano, M. ve Farrahi, G.H. (2014) An approach to relate shot peening finite element simulation to the actual coverage, Surface \& Coatings Technology 243, 39-45. doi: 10.1016/j.surfcoat.2012.03.057

3. Guechichi, H., Castex, L. ve Benkhettab, M. (2013) An analytical model to relate shot peening almen intensity to shot velocity, Mechanics Based Design of Structures and Machines 41, 79-99. doi:10.1080/15397734.2012.703607

4. Larose, G.S., Perron C., Bocher, P. ve Le'vesque M. (2013) On the effect of the peening trajectory in shot peen forming, Finite Elements in Analysis and Design 69, 48-61. doi.org/10.1016/j.finel.2013.02.003

5. Reilley, M. (2013) Product Design \& Development, Advantage Business Media. 
